\title{
Maternal health interventions in resource limited countries: a systematic review of packages, impacts and factors for change
}

\author{
Angelo S Nyamtema1*, David P Urassa ${ }^{2}$ and Jos van Roosmalen ${ }^{3,4}$
}

\begin{abstract}
Background: The burden of maternal mortality in resource limited countries is still huge despite being at the top of the global public health agenda for over the last 20 years. We systematically reviewed the impacts of interventions on maternal health and factors for change in these countries.

Methods: A systematic review was carried out using the guidelines for Preferred Reporting Items for Systematic Reviews and Meta-Analyses (PRISMA). Articles published in the English language reporting on implementation of interventions, their impacts and underlying factors for maternal health in resource limited countries in the past 23 years were searched from PubMed, Popline, African Index Medicus, internet sources including reproductive health gateway and Google, hand-searching, reference lists and grey literature.

Results: Out of a total of 5084 articles resulting from the search only 58 qualified for systematic review. Programs integrating multiple interventions were more likely to have significant positive impacts on maternal outcomes. Training in emergency obstetric care (EmOC), placement of care providers, refurbishment of existing health facility infrastructure and improved supply of drugs, consumables and equipment for obstetric care were the most frequent interventions integrated in 52\% - 65\% of all 54 reviewed programs. Statistically significant reduction of maternal mortality ratio and case fatality rate were reported in $55 \%$ and $40 \%$ of the programs respectively. Births in EmOC facilities and caesarean section rates increased significantly in $71 \%-75 \%$ of programs using these indicators. Insufficient implementation of evidence-based interventions in resources limited countries was closely linked to a lack of national resources, leadership skills and end-users factors.

Conclusions: This article presents a list of evidenced-based packages of interventions for maternal health, their impacts and factors for change in resource limited countries. It indicates that no single magic bullet intervention exists for reduction of maternal mortality and that all interventional programs should be integrated in order to bring significant changes. State leaders and key actors in the health sectors in these countries and the international community are proposed to translate the lessons learnt into actions and intensify efforts in order to achieve the goals set for maternal health.
\end{abstract}

\section{Background}

Reducing maternal mortality has been at the top of the global health agenda for over the last 20 years and we know that $74-98 \%$ of maternal deaths can be averted even in the circumstances of most low income countries $[1,2]$. The burden, however, is still huge and every year 0.36 million maternal deaths [3], 4 million stillbirths and

\footnotetext{
* Correspondence: nyamtema_angelo@yahoo.co.uk

${ }^{1}$ Tanzanian Training Centre for International Health, Ifakara, Tanzania

Full list of author information is available at the end of the article
}

3 million early neonatal deaths are related to complications of pregnancy and childbirth globally. This figure is by far higher than the total of 5 million estimated deaths due to HIV/AIDS, tuberculosis and malaria combined [4]. The vast majority (99\%) of estimated global maternal mortality occurs in resource limited settings, Sub Saharan Africa accounting for more than half $[3,5]$. While other regions like Latin America and the Caribbean, and Northern Africa had remarkably reduced maternal mortality ratio (MMR) by $41 \%$ and $59 \%$ respectively between 1990 and 2008, Sub Saharan Africa had only reduced it

\section{() Biomed Central}


by $26 \%$. The annual decrease of maternal mortality in Sub Saharan Africa was 1.7\% which is far below the 5.5\% annual decline rate, which is necessary to achieve the fifth Millennium Development Goal concerning maternal mortality reduction with three quarters [3]. The existing disparities of the trends in reducing maternal mortality in resource limited countries raise questions about the existing factors for change for replication of evidencebased interventions.

Maternal mortality is a complex problem requiring complex interventions. This article attempts to explore the available evidences, integration of maternal health interventions and the factors influencing implementation in resource limited countries. It challenges the key actors in resource limited countries to acknowledge the problem and scale up the means and advocated measures to address this scandal.

\section{Methods}

\section{Search strategy description}

This review used the guidelines for Preferred Reporting Items for Systematic Reviews and Meta-Analyses (PRISMA) [6]. A comprehensive literature search for relevant articles was carried out from PubMed, Popline, African Index Medicus, general internet sources including reproductive health gateway and Google, handsearching, reference lists and the grey literature. The following free terms were used for electronic searching: "maternal", "mortality", "interventions", "randomized controlled trials" and "emergency obstetric care indicators". With the help of information resource specialist the search details were designed according to specifications of each database (Additional file 1). The last search was carried out on June $30^{\text {th }} 2010$.

\section{Inclusion criteria}

We included randomized controlled trials (RCTs) and quasi-experimental designs with and those without control groups undertaken in resource limited countries that reported in English language the implementation of interventions, their impacts for maternal health within the past 23 years (i.e. from 1987 after launching the global Safe Motherhood Initiative in Nairobi, Kenya). The decision to start from 1987 was arbitrary and based on the need of reviewing recent data. Although the best and most objective way would have been to assess the impacts of these interventions by using RCTs, the investigators wanted also to review the evidences from quasiexperimental studies. By resource limited countries we meant low income (gross national income [GNI] per capita of $\$ 975$ or less) and lower middle income countries (GNI $\$ 976-\$ 3,855$ ) as classified in 2008 by The World Bank [7]. We included in the analysis only articles that clearly specified types of interventions, duration of implementation and used either MMR or at least one of the emergency obstetric care (EmOC) services indicators as outcome measures. We also extracted the underlying factors for maternal health interventions from the reviewed articles. These included factors which affected the implementation of interventions and all underlying reasons for insufficient implementation of maternal health interventions in these countries. Insufficient implementation was defined as poor coverage in terms of degree of integration of interventions and area as well as the efficiency of implementation. The investigators were interested in these factors because they could have affected the impacts of the interventions in these countries.

\section{Exclusion criteria}

We excluded articles reporting drug and procedural interventions addressing unique communities (like refugees) and individual medical conditions during pregnancy like malaria, anaemia and pre-eclampsia. Articles whose lists of interventions or implementation period were not clear, success reports over 23 years ago and those from countries other than low income and lower middle income were also excluded.

\section{Quality and risk of bias assessment}

The first author identified the articles, imported them into the EndNote $\mathrm{X}$ reference management software, removed the duplicates, examined the titles, then abstracts and retrieved the full text of relevant abstracts for further assessment (Figure 1). The first two authors independently assessed full-texts for inclusion in the review and completed the data extraction form for those that were eligible for inclusion. Uncertainties were resolved through discussions. Internal validation and generalizability of the included articles were carried out using a devised quality assessment tool (Additional file 2). The possibility of publication bias of RCTs and quasi-experimental designs with control groups was assessed using a funnel plot.

\section{Data collection and analysis}

A designed eligibility form was used to document all full-text articles assessed for eligibility, the judgment reached whether a study was eligible and reasons in case of exclusion. A data extraction form was used to collect all necessary information from eligible articles. This form had six sections designed to collect information on (i) general information of the articles: name of reviewer, title, authors, year of publication, type of study (ii) general characteristics of the project: country involved, setting (whether rural, urban or both), sources of funds (whether local, external or both), total period of implementation, (iii) implemented interventions, (iv) outcome 


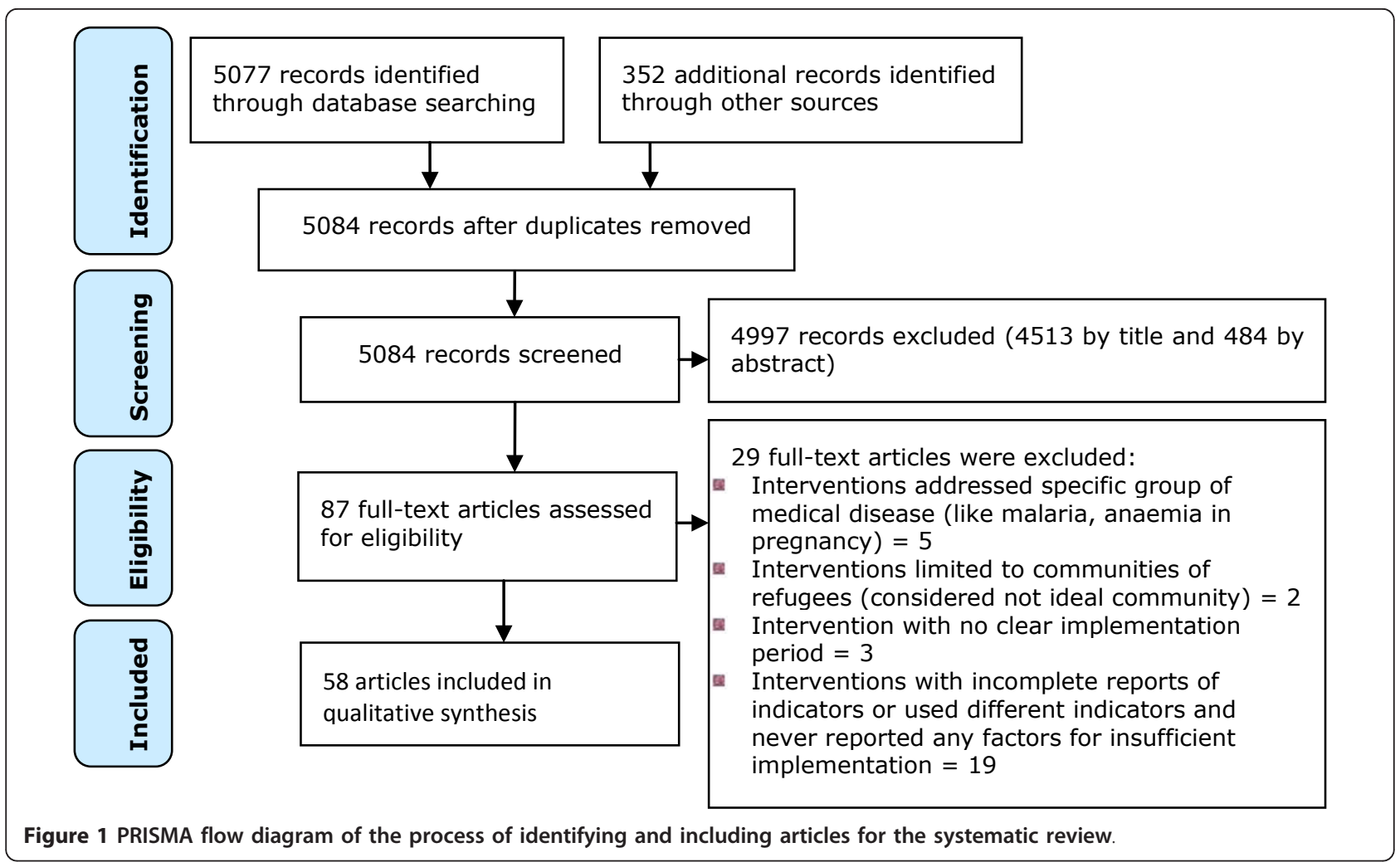

measures: results of interventions (v) underlying factors for implementation and (vi) quality and risk of bias. Indicators for outcome measures were changes in MMR and EmOC services indicators (also known as UN emergency obstetric care process indicators) i.e. case fatality rate (CFR), proportion of births in EmOC facilities, the met needs for EmOC and the caesarean section rate (CSR) before and after implementation of the intervention. Although the overtime changes of MMR may be confounded by a wide range of factors, it is generally acceptable as key health indicator used to evaluate the impacts of interventions for maternal care $[8,9]$. These indicators were preferred for this review because they are globally recommended for assessment, monitoring and evaluation of availability, utilization and quality of EmOC services [10]. All these items were entered initially into Excel software and then transferred to the Stata software for analysis. Supplementary information with a summary of characteristics of all studies included in this systematic review is available in the journal's website appendix (Additional file 3).

\section{Principal summary measures}

The raw data were extracted from these articles followed by computation of the odds ratio and $95 \%$ confidence intervals for all indicators used in these studies. Meta-analysis was not carried out because of wide variations of packages, time intervals and indicators used for outcome measures of interventions.

\section{Results}

Out of a total of 5084 articles published in English language resulting from the search, 87 full-text articles were assessed for eligibility. Of these only 58 qualified for systematic review and included 46 articles reporting maternal health interventional outcomes measured using MMR and/or EmOC services indicators. Of these 4 pairs of articles reported about the same programs and were thus merged to get a total of 42 interventional programs. Other articles included in this review were 12 interventional programs which used outcome measures other than MMR and EmOC services indicators but reported underlying factors for implementation in resource limited settings. The rest were excluded from the review with reasons (Figure 1).

The quality of RCTs and quasi-experimental designs with control groups were satisfactory as most of the information was from studies with low risk of bias (Figure 2). Expectedly there were more unclear and high risks of biases among the quasi-experimental designs without control groups than the former studies. Although the review team did not access the protocols for these studies (accessed only one [11]), no single study completed the set of EmOC services indicators and there was huge variability 


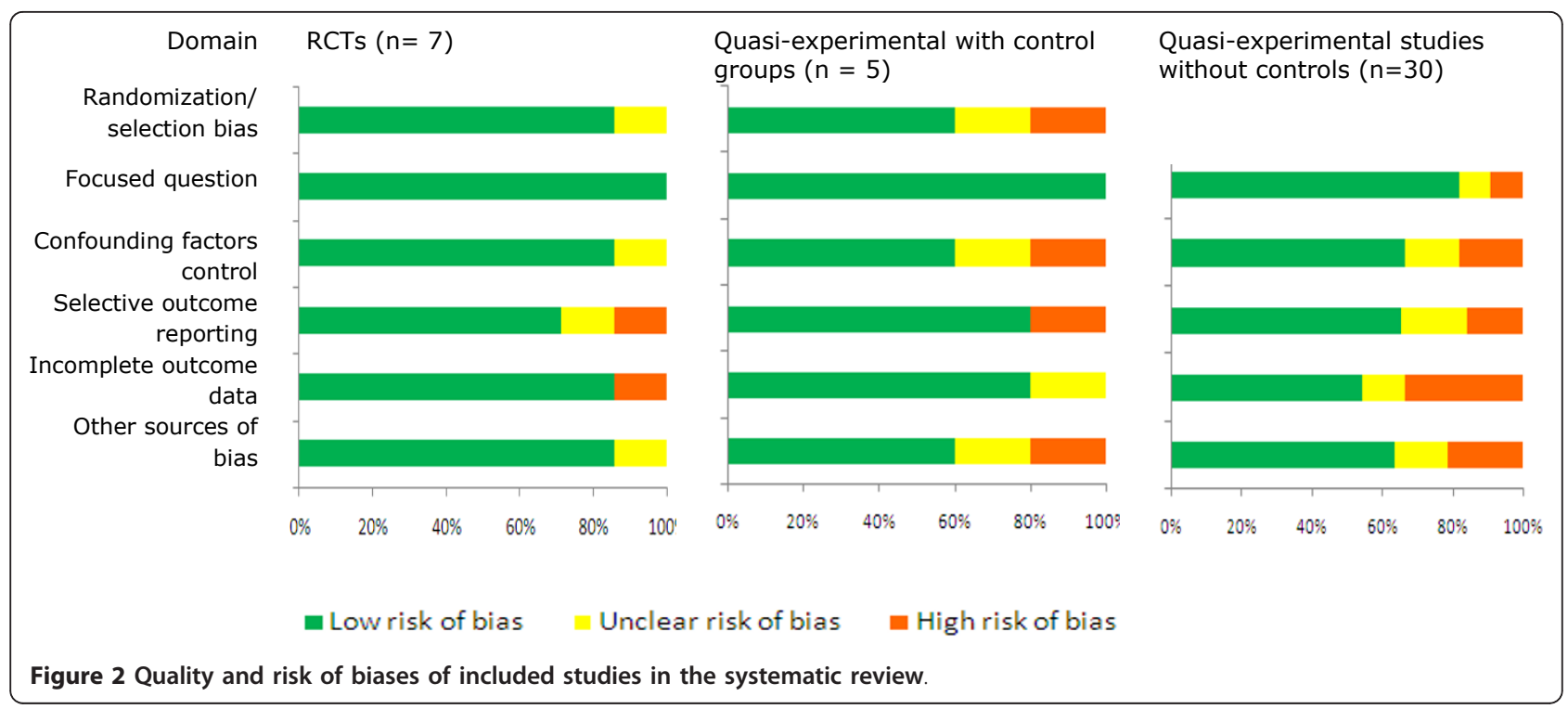

of the indicators across the studies suggesting the possibility of selective outcome reporting. The funnel plot for RCTs and quasi-experimental designs with control groups was asymmetrical suggesting increased possibility of high risk of publication bias especially for the small studies (Figure 3). However, this asymmetrical view could have been caused by other factors, such as differences in study qualities and heterogeneity. In view of this, the review team proceeded with further analysis although this selectivity posed a threat to the validity of the effects of the interventions.

\section{Implementation of the interventions}

Of all 42 interventional programs only 7 (17\%) were randomized controlled trials, 5 (12\%) quasi-experimental designs with control groups and the rest were quasiexperimental designs without control groups. From these interventional programs a list of interventions for maternal health was established (Table 1). The implementation processes of maternal health interventions followed almost the same simple logical framework with minimal variations (Figure 4). Mostly, the interventions were developed following descriptive retrospective reviews or needs assessments in the respective project areas which were conducted to identify the magnitude of the problem, the causes and underlying factors for the high ratios of maternal deaths. These pre-interventional studies were carried out in order to develop and implement more focused interventions. These activities were then followed by setting priorities, setting order of implementation of the interventions followed by monitoring and evaluation.

Despite the diversity of country contexts and the multifaceted nature of maternal health and its determinants, the interventions overlapped considerably with each other across the programs. Attempts were made to classify the interventions according to level of prevention: interventions targeted at preventing pregnancy (primary), preventing obstetric complications (secondary) and preventing death once obstetric complications had occurred (tertiary prevention).

Training in comprehensive EmOC, placement and motivation of care providers, refurbishing existing health facility infrastructure and improving supply of essential drugs, consumables and equipment for obstetric care were the most frequent interventions integrated in 52\% - $65 \%$ of the programs. Community-based information, education and communication (IEC) were involved in $37 \%$ (20) of the programs. The IEC addressed the danger signs of pregnancy complications, birth preparedness and complication readiness in an attempt to shorten delays through better awareness and promoting health facility deliveries.

The success of these programs was attributed to increased health facility deliveries, knowing when to reach out for assistance, and increased awareness and knowledge of the danger signs of pregnancy complications. Interventions which focused on linking traditional birth attendants (TBAs) with the health care system were implemented in various countries including Gambia, Honduras and some provinces in China. The training focused on creating TBAs' awareness of the importance and practice of clean delivery and early referral to the formal health care system with essential obstetric services to avoid delays in case of complications. Training of TBAs in countries where the community commonly utilized their services had strong impacts on maternal health outcomes only when it was 


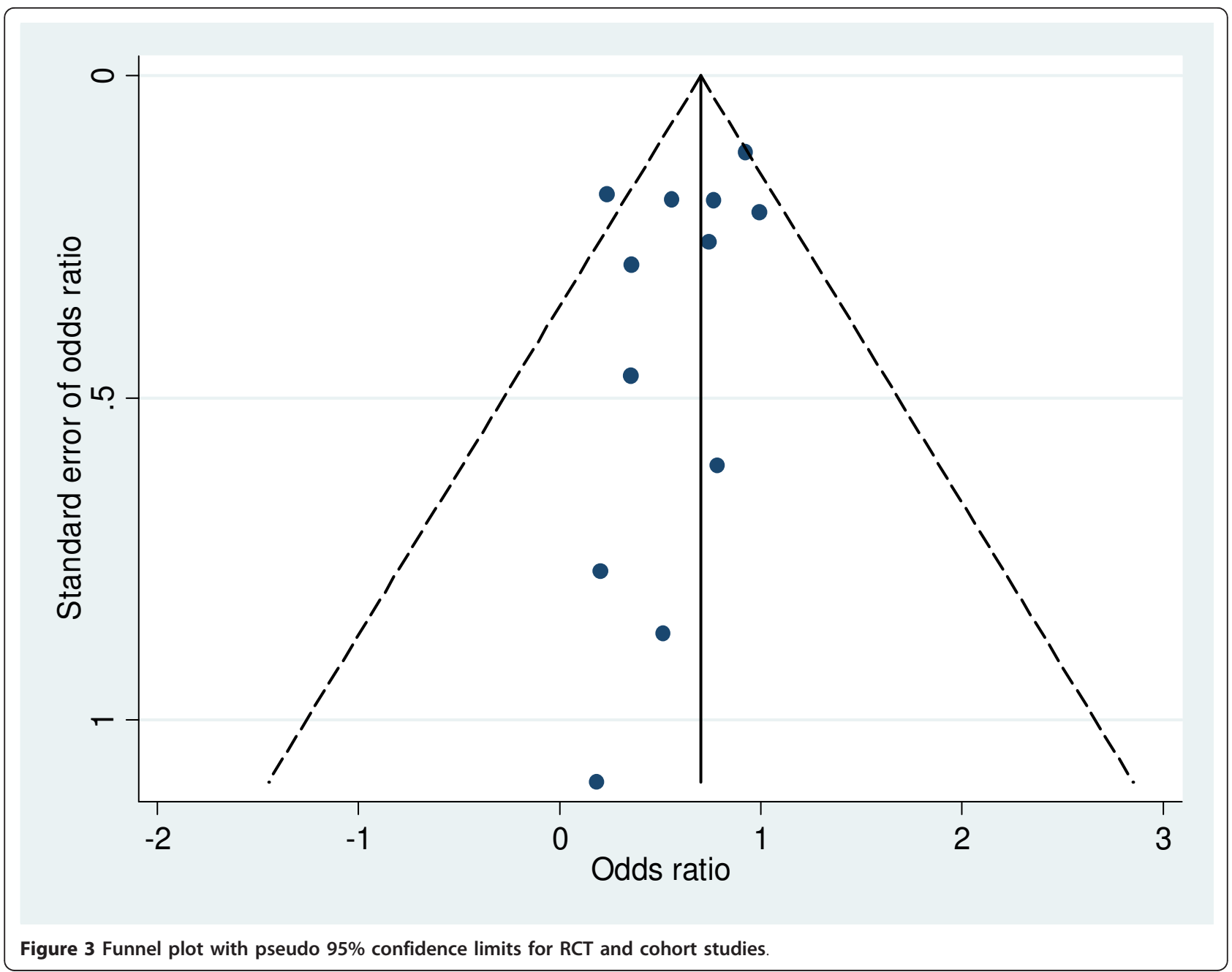

supported by functioning referral systems and good working relationships with the formal health care systems.

All 22 interventional programs for maternal health from Sub Saharan Africa were small scale mainly confined to a hospital (district or state) and/or small surrounding communities. Countrywide reduction of MMR was reported in China, Bangladesh, Nepal, Honduras and Bolivia. In these countries the efforts targeted specific geographic areas with high ratios of maternal mortality with special attention to the most remote rural areas. The interventions included development of health facility accountability like health facility performance based funding (in some Chinese provinces), development of financing systems like community based funds and removing financial barriers to maternal health care services like the establishment of Maternal and Child National Insurance (Bolivia, China and Nepal). These policies were reported to increase women's access to skilled attendance.

\section{Impacts of the interventions}

A wide range of indicators were used to assess the impacts of these maternal health care interventions. Depending on the type of intervention the most frequently used outcome (impact) indicators were MMR (67\%) and EmOC services indicators (52\%). Other indicators (not included in the analysis) were mean time from onset of complications/or admission to treatment, number of referred patients, utilization of obstetric and blood services, community awareness and knowledge on obstetric care. Of all RCTs only a study from Pakistan used at least one EmOC services indicator in addition to MMR. While only 2 (29\%) RCTs reported statistically significant maternal mortality reduction, significant reduction was found in as high as 60\% (3) of quasiexperimental designs with control groups (Table 2).

Maternal mortality ratio was remarkably reduced by as high as $80 \%$ from 933 to $186 / 100,000$ live births (OR = $0.20,95 \% \mathrm{CI}=0.09-0.44$ ) for only 6 years using exclusively locally available resources as reported from one of 
Table 1 Category, frequency and level of prevention of the interventions for maternal health extracted from the included programs

\begin{tabular}{|c|c|c|c|}
\hline SN & Category of interventions & $\begin{array}{l}\text { Level of } \\
\text { prevention }\end{array}$ & $\begin{array}{c}\text { Frequency/ } \\
\text { percentage } \\
\mathrm{n}=54\end{array}$ \\
\hline \multicolumn{4}{|c|}{ Community based interventions } \\
\hline 1. & $\begin{array}{l}\text { Community based Information, Education and Communication: } \\
\text { Focus: awareness of danger signs of pregnancy complications and birth preparedness and importance of health facility } \\
\text { delivery services }\end{array}$ & 2,3 & $20(37 \%)$ \\
\hline 2 & Establishing community based funds for obstetric complications [loans and/or transport programs]: & 2 & $10(19 \%)$ \\
\hline 3 & $\begin{array}{l}\text { Training and/or linking traditional birth attendants to the health system: } \\
\text { Focus: Clean delivery and shorten delays for complications of pregnancy and childbirth. }\end{array}$ & 2,3 & $15(28 \%)$ \\
\hline 4 & $\begin{array}{l}\text { Supplementing vitamin } A \text { or } \beta \text { carotene during pregnancy: } \\
\text { To prevent infectious maternal morbidity and mortality }\end{array}$ & 2 & $2(4 \%)$ \\
\hline \multicolumn{4}{|c|}{ Health facility based interventions } \\
\hline 5 & Establishing/refurbishing blood banks and blood policies & 3 & $11(20 \%)$ \\
\hline 6 & Training on CEmOC, placement and motivation of care providers & 3 & $35(65 \%)$ \\
\hline 7 & Refurbishing/upgrading existing health facility infrastructure and equipment for obstetric care & 3 & $28(52 \%)$ \\
\hline 8 & Improving supply of drugs, consumables and equipment for obstetric care & 3 & $30(56 \%)$ \\
\hline 9 & Strengthening referral system and transport of patients & 2,3 & $25(46 \%)$ \\
\hline 10 & Construction of new health facilities for CEmOC services & 2 & $2(4 \%)$ \\
\hline 11 & $\begin{array}{l}\text { Enabling policies and political commitment: } \\
\text { Focus: To increase health facility utilization and accessibility of essential obstetric care services }\end{array}$ & $1,2,3$ & $10(19 \%)$ \\
\hline 12 & Establishment of revolving funds at the EmOC health facility & 3 & $4(7 \%)$ \\
\hline 13 & Establishing family planning services & 1 & $3(6 \%)$ \\
\hline 14 & Establishing maternity waiting homes & 2 & $1(2 \%)$ \\
\hline 15 & Establishing mobile maternal health services, outreach and/or supportive supervision programs & 2 & $7(13 \%)$ \\
\hline 16 & Improving and/or promoting antenatal care & 2,3 & $6(11 \%)$ \\
\hline
\end{tabular}

*Level 1: primary prevention (preventing pregnancy; 2: secondary prevention (preventing obstetric complications); 3 : tertiary prevention (preventing death once obstetric complications have occurred).

EXISTING LEVEL OF CARE \& MAGNITUDE OF THE PROBLEM

\section{Step I: Retrospective review: Gap analysis}

1. Identify areas of unmet need

2. Describe the pattern of the problem

3. Identify underlying factors for the gaps

Step II: Implementation

1. Select required interventions: what should be done?

2. Set priorities for improvement: what can be afforded?

3. Plan for sustainability of the program and achievements: involve all stakeholders

4. Set order of implementation

5. Implement the set of interventions according to the agreed order

\section{Step III: Monitoring and Evaluation}

1. Develop evaluation work plan

2. Determine regularly the implementation successes, constraints and recommend on the way forward.

EXPECTED LEVEL OF PREGNANCY CARE \& OUTCOME

Figure 4 Logical Systematic Implementation Framework for Maternal Health Interventions. 
Table 2 The packages of interventions and their impacts for maternal health in resource limited countries

\begin{tabular}{|c|c|c|c|c|c|}
\hline \multirow[t]{2}{*}{ Country } & \multirow{2}{*}{$\begin{array}{c}\text { Integrated } \\
\text { interventions } \\
\text { (from table } 1)^{*}\end{array}$} & \multirow{2}{*}{$\begin{array}{c}\text { Time } \\
\text { Interval } \\
\text { (years) }\end{array}$} & \multicolumn{2}{|l|}{$\begin{array}{l}\text { Maternal } \\
\text { deaths/live births }\end{array}$} & \multirow[t]{2}{*}{$\begin{array}{l}\text { Odds ratio } \\
(95 \% \mathrm{Cl})\end{array}$} \\
\hline & & & Intervention & Control & \\
\hline \multicolumn{6}{|c|}{ Randomized controlled trials } \\
\hline Zimbabwe [26] & 16 & 2 & $6 / 9,394$ & $5 / 6,138$ & $0.78(0.24-2.57)$ \\
\hline Zimbabwe [27] & 16 & 3 & $2 / 6,483$ & $4 / 6,696$ & $0.52(0.09-2.82)$ \\
\hline Pakistan [28] & 3,15 & 2 & $27 / 10,093$ & $34 / 9,432$ & $0.74(0.45-1.23)$ \\
\hline India [29] & 1 & 3 & 49/9,388 & $60 / 8,819$ & $0.77(0.52-1.12)$ \\
\hline Nepal [30] & 4 & 3.5 & $59 / 14,948$ & $51 / 7,241$ & $0.56(0.37-0.84)$ \\
\hline Nepal [31] & 1 & 3 & $2 / 2,899$ & $11 / 3,226$ & $0.20(0.04-0.91)$ \\
\hline Ghana [11] & 4 & $29 \times 10^{3 \S}$ & $138 / 39,601$ & $148 / 39,234$ & $0.92(0.73-1.17)$ \\
\hline \multicolumn{6}{|c|}{ Quasi-experimental designs with control groups } \\
\hline Angola [32] & 3,6 & 4 & $55 / 18,755$ & $66 / 5,363$ & $0.24(0.16-0.34)$ \\
\hline Gambia [33] & $3,6,9,15,16$ & 3 & $1 / 769$ & $5 / 714$ & $0.43(0.02-1.55)$ \\
\hline Bangladesh [34] & $3,6-9,15,16$ & 3 & $6 / 4,424$ & $20 / 5,206$ & $0.35(0.66-0.89)$ \\
\hline Bangladesh $^{\phi}[35]$ & $1,3,6-9,13,16$ & 4 & $41 / 10,890$ & $50 / 13,169$ & $0.99(0.66-1.50)$ \\
\hline Gambia [36] & $3,8,9$ & 7 & $11 / 405$ to $13 / 1,236$ & $4 / 267$ to $7 / 727$ & $0.36(0.20-0.64)$ \\
\hline \multicolumn{3}{|c|}{ Quasi-experimental designs without control groups } & After intervention & $\begin{array}{l}\text { Before } \\
\text { intervention }\end{array}$ & \\
\hline Egypt $[1,37]$ & $1,6-9,11$ & 7 & $585 / 696,428$ & $772 / 443,678$ & $0.48(0.43-0.54)$ \\
\hline Senegal [38] & $5-8,15$ & 3 & $27 / 6,622$ & $50 / 6,017$ & $0.49(0.30-0.80)$ \\
\hline Pakistan $[39,40]$ & $3,9,11,13,15,16$ & 5 & $34 / 52,982$ & $48 / 55,454$ & $0.74(0.48-1.15)$ \\
\hline Tanzania [41] & $5,6,7,8$ & 5 & $8 / 4,296$ & $28 / 3,000$ & $0.20(0.09-0.44)$ \\
\hline Peru [42] & $1,6,7,9,15$ & 4 & $2 / 3,119$ & $9 / 3,002$ & $0.21(0.05-0.99)$ \\
\hline Nigeria [43] & $5,6,7,8$ & 6 & $7 / 1208$ & 47/2999 & $0.37(0.17-0.81)$ \\
\hline Nigeria $[44,45]$ & $1,2,6,7,8$ & 6 & $7 / 815$ & $44 / 861$ & $0.16(0.07-0.36)$ \\
\hline Nigeria [46,47] & $2,5-8,12$ & 5 & 0/130 & 1/139 & $0.53(0.02-16.02)$ \\
\hline Bangladesh [48]† & $1,3,9,13,16$ & 13 & $86 / 46,320$ & $299 / 10^{5}$ & 0.62 \\
\hline Cameroon [49]† & 6,9 & 10 & $60 / 10^{5}$ & $260 / 10^{5}$ & 0.23 \\
\hline China [1]† & $1,3,5-9,11$ & 16 & $61 / 10^{5}$ & $100 / 10^{5}$ & 0.61 \\
\hline China [50]† & $1,3,6,9,11$ & 3 & $114 / 10^{5}$ & $456 / 10^{5}$ & 0.25 \\
\hline Honduras [51]† & $1,3,6-9,14$ & 7 & $108 / 10^{5}$ & $182 / 10^{5}$ & 0.59 \\
\hline Bolivia [1,52]† & $7-9,11$ & 11 & $230 / 10^{5}$ & $390 / 10^{5}$ & 0.59 \\
\hline India [53]† & $6-11$ & 14 & $90 / 10^{5}$ & $380 / 10^{5}$ & 0.24 \\
\hline Nepal [54]† & $1,2,5-8,11$ & 10 & $281 / 10^{5}$ & $539 / 10^{5}$ & 0.52 \\
\hline
\end{tabular}

Note: *The numbers given to the interventions correspond to those given in table 1; § Follow up years (the interventions were started in 2000 - 2008 but at different times across the clusters); ${ }^{\phi}$ Interventions were implemented at various intervals and we analyzed results from the last 4 years when a complete package was implemented. + Odds ratio was calculated from MMR before and after intervention due to incomplete raw data in the review articles.

the regional hospitals in Tanzania (Table 3). Similarly, only $40 \%$ (6) of programs which used CFR to assess impact of their interventions reported statistically significant reduction. The four most successful interventional programs reduced CFR by over three quarters (i.e. 77\% $100 \%)$. The met need for EmOC was used as an outcome measure indicator in only 10 reports and the mean increase was as high as $149 \%$ (ranging from $24 \%$ to $444 \%$ ) after a mean period of 5 years. Even the nine interventional programs which lacked community-based packages reported increased institutional deliveries by an average of $74 \%$ after a mean period of 6 years of health facility quality care improvement and development of enabling policies.

\section{Factors for change}

The problem of insufficient implementation of maternal health interventions was generally attributed to three main interlinking factors i.e. leadership and management, resources and end-user related factors. The leadership and management related factors included insufficient commitment of politicians and other key actors which led to insufficient funding of health systems, under utilization of available resources, lack of 
Table 3 Impacts of interventions for maternal health in quasi-experimental studies without control groups in resource limited countries

\begin{tabular}{|c|c|c|c|c|c|}
\hline \multirow[t]{2}{*}{ Country } & \multirow{2}{*}{$\begin{array}{l}\text { Interventions } \\
\text { (from table 1)* }\end{array}$} & \multirow{2}{*}{$\begin{array}{c}\text { Time } \\
\text { Interval } \\
\text { (years) }\end{array}$} & \multicolumn{3}{|c|}{ Odds ratio and $95 \% \mathrm{Cl}$ of EmOC services indicators } \\
\hline & & & $\begin{array}{l}\text { Births in EmOC } \\
\text { facility }\end{array}$ & CFR & CSR \\
\hline Tanzania [55] & $5-8$ & 4 & $3.00(1.46-6.18)$ & $0.66(0.11-4.04)$ & $1.51(0.15-15.46)$ \\
\hline Ethiopia [55] & $6,7,8$ & 4 & $1.26(0.15-10.23)$ & $0.47(0.16-1.44)$ & $1.64(1.50-1.80)$ \\
\hline Bangladesh [56] & $1,6-8,11$ & 6 & $2.36(2.33-2.39)$ & $0.04(0.03-0.05)$ & $2.00(0.37-10.97)$ \\
\hline Mali [57] & $2,6,8,9$ & 3 & $2.78(2.70-2.86)$ & $0.48(0.32-0.73)$ & $1.09(0.94-1.25)$ \\
\hline Peru [42] & $1,6,7,9,15$ & 4 & $0.96(0.91-1.02)$ & $0.06(0.00-34.26)$ & $2.53(1.93-3.33)$ \\
\hline Rwanda [58] & $6,7,8$ & 4 & $0.94(0.88-0.99)$ & $0.56(0.26-1.20)$ & $1.59(1.41-1.60)$ \\
\hline Mozambique [59] & $6,7,8,9$ & 4 & $3.91(3.80-4.02)$ & $0.54(0.35-0.84)$ & - \\
\hline Tanzania [60] & 1 & 2 & $41(10-171)$ & - & \\
\hline India [53] & $6-11$ & 15 & $4.13(1.99-8.55)$ & - & - \\
\hline Nepal [54] & $1,2,5-8,11$ & 10 & $2.52(1.04-6.11)$ & - & - \\
\hline Vietnam [61]+† & $6-9,15$ & 4 & $\begin{array}{l}3.11(2.53-3.82) \\
1.2(0.99-1.46)\end{array}$ & - & $\begin{array}{l}38(2-636) \\
1.43(1.02-1.99)\end{array}$ \\
\hline Pakistan [62] & $3,6,16$ & 2.5 & $2.04(1.83-2.28)$ & - & $1.44(1.09-1.91)$ \\
\hline Mozambique [63]† & $7,8,9,10$ & 3 & $8.61(8.04-9.23)$ & - & $2.69(2.54-2.85)$ \\
\hline Senegal [38] & $5-8,15$ & 3 & - & $0.42(0.09-1.84)$ & $2.75(0.27-27.72)$ \\
\hline Tanzania [41] & $5,6,7,8$ & 5 & - & $0.32(0.21-0.48)$ & $3.83(1.63-8.99)$ \\
\hline Nigeria [43] & $5,6,7,8$ & 6 & - & $0.72(0.31-1.66)$ & $1.12(1.07-1.17)$ \\
\hline S Leone [64] & $1,6-8,12$ & 6 & - & $0.11(0.03-0.36)$ & $1.68(1.50-1.87)$ \\
\hline Nigeria [65] & $2,6,7,8$ & 4 & - & $0.89(0.31-2.61)$ & $17(1-300)$ \\
\hline Nigeria $[44,45]$ & $1,2,6,7,8$ & 6 & - & $0.17(0.07-0.39)$ & - \\
\hline S Leone $[66,67]$ & $1,2,5,6,9$ & 3 & - & $0.43(0.08-2.21)$ & - \\
\hline Nigeria $[46,47]$ & $2,5-8,12$ & 5 & - & $0.17(0.01-4.74)$ & - \\
\hline
\end{tabular}

Note: *The numbers given to the interventions correspond to those given in table 1; CSR = caesarean section rate; CFR = case fatality rate; + Only one part of the report is included here as the program had other sites and the data were not combined. †† Had two interventional areas: a) Hai Lang district hospital and b) Hoang Hoa district hospital.

enabling policies for maternal health care, poor management, misplacement of priorities and lack of credibility, loyalty to the assignments, innovativeness and leadership skills. Other leadership and management related factors were social and political instabilities as reported in Angola and Sierra Leone. On the contrary, remarkable successes in reducing maternal mortality in China, Egypt, Honduras, Bangladesh and Bolivia (reported above) were attributed to strong political commitment, good leadership in reproductive health and presence of enabling policies.

Eleven articles linked insufficient implementation of maternal health interventions to lack of resources. These included limited national budgets for health care versus high costs required to scale up maternal health interventions. Under-funding of health systems resulted into lack of essential drugs, supplies and equipment, insufficient health facilities and qualified human resources as well as inefficient referral systems. The review indicated that more than three quarters $(80 \%)$ of all included interventional programs were supported by the international donor community.
Four articles cited a pattern of end-user factors which were by large linked to cultural, low social and economic status and nutrition. Illiteracy and cultural factors like lack of autonomy in the decision-making process, early marriages and dietary practices during pregnancy affected nutrition, access to health services and community participation in implementation of maternal health interventions. In places where enabling policies did not exist as reported in Nigeria and Sierra Leone, poverty affected utilization of obstetric care services.

\section{Discussion}

This study has revealed a heterogeneous picture for the nature, extent of integration of interventions and results. Generally, RCTs revealed insignificant impact of the interventions for maternal health. This could be explained partly by the fact that almost all (86\%) RCTs studied the impact of single interventions and were implemented for shorter periods as opposed to quasiexperimental programs which integrated multiple interventions and for longer periods. These findings suggest that no single magic bullet intervention exists for 
reduction of maternal mortality and that all interventional programs should be integrated in nature in order to bring significant changes [12].

On the other hand, results from quasi-experimental studies constituted the body of evidence of the effectiveness of packages of interventions for maternal health across a wide range of settings especially when these are integrated. Findings from previous systematic reviews on maternal health interventions complement the evidences $[5,13,14]$. The degree of integration of these interventions depends on the context and the determinants of maternal health in the respective communities.

This study has indicated that most programs focused generally on promoting accessibility and utilization of health facility delivery services as well as improving the quality of care. All programs which most successfully reduced maternal mortality and remarkable EmOC indicators, had established functioning maternal health care systems with access to skilled birth attendants equipped with appropriate drugs, supplies and equipments and systems of referral to higher levels of care in the event of obstetric complications. Such successes could be explained by the fact that most maternal deaths occur during the period around giving birth, and that most life-threatening obstetric complications arise suddenly without warning signs and hence require appropriate and timely management [15]. The degrees of the impacts were associated with the type of packages of interventions, degree of integration, duration and efficiency of implementation, the presence of enabling policies and the magnitude of the problem before implementation. The logic dictates that the higher the CFR and MMR, the higher are the chances of attaining greater impacts in these indicators after implementation of effective interventions.

The degree of implementation of maternal health interventions and approaches were uneven across the regions. While the programs in Asia and North Africa tried to cover wide areas and range of interventions, those from Sub Saharan Africa were mostly confined to one or few health facilities and the surrounding communities. These findings can partly explain huge disparities in the progress achieved in reducing maternal mortalities among regions $[8,16]$.

On the other hand, although wealth was one of the factors for maternal health care and hence MMR at the country level, it has been reported that, there is no straightforward relationship between the two, and that health system responsiveness has an explanatory power that is significantly superior to most other factors $[17,18]$. Huge disparities of MMRs exist even among countries with similar low economic powers. For instance, from 1980 to 2008 with the GNI per capita of 1,000 US\$ Lesotho and Ivory Coast had increased MMR from 590/100,000 live births to 964 - 994/100,000 live births, while Bangladesh with even less income (520 US \$) decreased MMR from 1329/100,000 live births to as low as 338/100,000 live births. Similarly, between 1980 and 2008 with GNI per capita between 200 US\$ and 400 US\$, Nepal successfully reduced MMR from 864/ 100,000 live births to $240 / 100,000$ live births, but MMR remained almost unchanged in Sierra Leone (1240 to $1033 / 100,000$ live births) and remarkably increased in Malawi from 632/100,00 live births to as high as 1140/ 100,000 live births [5,7].

Quite often lack of good quality leadership within the public service has been more closely linked to poor performance of the public sectors than to a lack of national resources $[19,20]$. The under-funding of the health systems in countries whose governments signed the Millennium Declaration in 2000, committed to reduce maternal mortality with $75 \%$ by 2015 , and failure of most Sub Saharan African countries to meet the Abuja Commitment to allocate at least $15 \%$ of the national budget to the health sector reflect irresponsible commitments of these states' leaders. The problem of irresponsible commitments and lack of accountability can be tracked from the states' leaders and key health managers down to the care providers' level [21]. As a central factor, the health sectors in resource limited countries particularly in Sub Saharan Africa require more proactive leaders with stronger internal desire for change to turn commitments and promises into resources and actions in order to reduce maternal mortality. Leadership is a change agent, is all about getting things done and taking on the responsibility to influence others [22].

Based on these findings, a list of short and medium term strategies for action is proposed for countries with insufficient implementation of maternal health interventions. These include mobilizing political will and commitment, leadership development strategies, establishment of performance management and appraisal systems to enhance creativity and innovations in the domain of reproductive health, strengthen community participation, integrating non-governmental organizations into motherhood programs, sharing information within and among countries and empowering women with education, autonomy and economy [23-25].

\section{Potential limitations of the study}

The increased possibility of publication and selective outcome reporting biases found in this study pose a great challenge, not only to the validity of the results of this review but also to investigators and editors of journals. Such biases indicate that only positive findings are reported and/or published. This may be misleading the global community with regards to policy and decision making on what interventions are effective for maternal 
health. The small number of articles reporting on the impacts of maternal health interventions using the stated indicators might have been contributed by language limitation (English). However, attempts were made to identify reports through a comprehensive literature search of relevant articles although some reports may have been missed. The fact that this review was limited to health sector interventions poses another limitation to this study.

\section{Conclusions}

Success stories in the context of maternal mortality reduction exist around the world even in countries with limited resources. The compiled evidences in this article strongly suggest that it is possible to reduce maternal mortality in the circumstances of resource limited countries if the state and health sectors' key actors realize their commitments and responsibilities, embark upon the underlying factors and intensify efforts to implement the evidence-based interventions. These findings indicate that no single magic bullet intervention exists for reduction of maternal mortality and that all interventional programs should be integrated in nature in order to bring significant changes. This article presents a list of the evidenced-based packages of interventions, the context of leadership in healthcare today and proposes to the local governments, intergovernmental agencies, donors and the international community an evidencebased approach for effective change in the health sectors in resource limited countries in order to achieve the goal set for maternal survival.

\section{Additional material}

Additional file 1: Detailed search strategies for each database involved in the systematic review. The detailed search strategies specific for each database involved in the systematic review.

Additional file 2: Quality assessment tool for included articles. A detailed structure of the tool used to assess the quality and risks of biases for included articles in the systematic review.

Additional file 3: Characteristics of all studies included in the systematic review: supplementary material. This table is a supplementary material with a detailed account of the characteristics of all studies included in this systematic review. These characteristics include the study population, setting, sample size, intervention and outcomes.

\section{Abbreviations}

AIDS: Acquired Immunodeficiency Syndrome; Cl: Confidence interval; CFR: Case fatality rate; CSR: Caesarean section rate; EmOC: Emergency obstetric care; HIV: Human immunodeficiency virus; IEC: Information, education and communication; MMR: Maternal mortality ratio; OR: Odds ratio; PRISMA: Preferred Reporting Items for Systematic Reviews and Meta-Analyses; RCT: Randomized controlled trials; TBA: Traditional birth attendant.
\end{abstract}

\section{Acknowledgements}

The authors wish to thank Heka Mapunda, a senior information resource specialist, for assisting with the search strategy.

\section{Author details}

${ }^{1}$ Tanzanian Training Centre for International Health, Ifakara, Tanzania. ${ }^{2}$ Department of Community Health, School of Public Health and Social Sciences, Dar es Salaam, Tanzania. ${ }^{3}$ Department of Obstetrics, Leiden University Medical Centre, The Netherlands. ${ }^{4}$ Department of Medical Humanities, EMGO Institute for Health and Care Research, VU Medical Centre, Amsterdam, The Netherlands.

\section{Authors' contributions}

ASN participated in design of the study, searched the literature, reviewed the papers and drafted the manuscript. DPU participated in design of the study, reviewed the papers and contributed to writing of the manuscript. JVR participated in design of the study, advised on content and contributed to writing of the manuscript. All authors read and approved the final manuscript.

\section{Competing interests}

The authors declare that they have no competing interests.

Received: 30 July 2010 Accepted: 17 April 2011 Published: 17 April 2011

\section{References}

1. Koblinsky M: Reducing Maternal Mortality. Learning from Bolivia, China, Egypt, Honduras, Indonesia, Jamaica, and Zimbabwe. Washington, D.C: The World Bank; 2003.

2. Prual A, Bouvier-Colle MH, de Bernis L, Breart G: Severe maternal morbidity from direct obstetric causes in West Africa: incidence and case fatality rates. Bull World Health Organ 2000, 78:593-602.

3. WHO, UNICEF, UNFPA, The World Bank: Trends of maternal mortality: 1990 to 2008 estimates developed by WHO, UNICEF, UNFPA and The World Bank. Geneva: WHO Press; 2010.

4. Tinker A, Koblinsky M, Daly P, Rooney C, Leighton C, Griffiths M, Zahidul A, Kwast B: Making motherhood safe (World Bank Discussion Paper, No. 202). Washington, DC: The World Bank; 1993.

5. Hogan MC, Foreman KJ, Naghavi M, Ahn SY, Wang M, Makela SM, Lopez AD, Lozano R, Murray C: Maternal mortality for 181 countries, 1980-2008: a systematic analysis of progress towards Millennium Development Goal 5. Lancet 2010, 375:1609-1623.

6. Liberati A, Altman DG, Tetzlaff J, Mulrow C, Gøtzsche C, loannidis JPA, Clarke M, Devereaux PJ, Kleijnen J, Moher D: The PRISMA Statement for Reporting Systematic Reviews and Meta-Analyses of Studies That Evaluate Health Care Interventions: Explanation and Elaboration. PLOS Med 2009, 6(7):e1000100.

7. The World Bank: Country Classifications. 2008 [http://data.worldbank.org/ about/country-classifications].

8. WHO: Maternal mortality in 2005: estimates developed by WHO, UNICEF, UNFPA and The World Bank. Geneva: WHO Press; 2007.

9. Maine D, Akalin MZ, Ward VM, Kamara A: The design and evaluation of maternal mortality programs. Center for Population and Family Health Columbia University, New York; 1997.

10. WHO/UNFPA/UNICEF/AMDD: Monitoring emergency obstetric care: a hand book. Geneva: World Health Organization; 2009.

11. Kirkwood BR, Hurt L, Amenga-Etego S, Tawiah C, Zandoh C, Danso S, Hurt C, Edmond K, Hill Z, Ten Asbroek G, et al: Effect of vitamin A supplementation in women of reproductive age on maternal survival in Ghana (ObaapaVitA): a cluster-randomised, placebo-controlled trial. Lancet 2010, 375:1640-1649.

12. Maine D: Lessons for program design from the PMM projects. Int J Gynecol Obstet 1997, 59(Suppl 2):259-265.

13. Kidney E, Winter HR, Khan KS, Gülmezoglu AM, Meads CA, Deeks JJ, Christine MacArthur C: Systematic review of effect of community-level interventions to reduce maternal mortality. BMC Pregnancy Childbirth 2009, 9:2.

14. Ross L, Simkhada P, Smith WC: Evaluating effectiveness of complex interventions aimed at reducing maternal mortality in developing countries. J Public Health 2005, 27:331-337.

15. Starrs A: Improve access to good quality maternal health services. The safe motherhood action agenda: Priorities for the next decade Colombo: Family Care International; 1997, 29-50.

16. Bryce J, Daelmans B, Dwivedi A, Fauveau V, Lawn JE, Mason E, Newby H, Shankar A, Starrs A, Wardlaw T: Countdown to 2015 for maternal, 
newborn, and child survival: the 2008 report on tracking coverage of interventions. Lancet 2008, 371:1247-1258.

17. Van Lerberghe $W$, De Brouwere V: Reducing maternal mortality in a context of poverty. In Safe motherhood strategies: a review of the evidence. Edited by: De Brouwere V, Van Lerberghe W. Antwerp: ITGPress; 2001:1-6.

18. Maternal mortality and poverty. [http://www.jsieurope.org/docs/ maternal_mortality_and_poverty.pdf].

19. Alihonou E: Africa: time for action. Plan Parent Chall 1998, , 1: 15.

20. Charlesworth K, Cook P, Crozier G: Leading change in the public sector: making the difference. London: Chartered Management Institute; 2003.

21. Nyamtema A, Urassa D, Pembe A, F K, van Roosmalen J: Factors for change in maternal and perinatal audit systems in Dar es Salaam hospitals, Tanzania. BMC Pregnancy Childbirth 2010, 10:29.

22. Martin V: Leading change in health and social care. Roultedge; 2003.

23. Safe motherhood South Asia: challenge for the nineties. IPPF Med Bull 1990, 24:1-3

24. WHO: The road to safe motherhood. Harare, Zimbabwe, WHO, Regional Office for Africa; 2001, 5: 11

25. WHO, UNFPA, UNICEF, World Bank: Saving mothers' lives: joint agency statement on reducing maternal mortality. Entre Nous Winter-Spring 2001, 49:11

26. Munjanja SP, Lindmark G, Nystrom L: Randomised controlled trial of a reduced-visits programme of antenatal care in Harare, Zimbabwe. Lancet 1996, 348:364-369.

27. Majoko F, Munjanja SP, Nyström L, Mason E, Lindmark G: Randomised controlled trial of two antenatal care models in rural Zimbabwe. BJOG 2007, 114:802-811

28. Jokhio A, Winter $\mathrm{H}$, Cheng K: An intervention involving traditional birth attendants and perinatal and maternal mortality in Pakistan. $N$ Engl $J$ Med 2005, 352:2091-2099.

29. Tripathy P, Nair N, Barnett S, Mahapatra R, Borghi J, Rath S, Rath S, Gope R, Mahto D, Sinha R, et al: Effect of a participatory intervention with women's groups on birth outcomes and maternal depression in Jharkhand and Orissa, India: a cluster-randomised controlled trial. Lancet 2010, 375:1182-1192

30. West K, Katz J, Khatry S, LeClerq S, Pradhan E, Shrestha S, Connor P, Dali S, Christian P, Pokhrel R, et al: Double blind, cluster randomised trial of low dose supplementation with vitamin $A$ or $\beta$ carotene on mortality related to pregnancy in Nepal. BMJ 1999, 318:570-575.

31. Manandhar DS, Osrin D, Shrestha BP, Mesko N, Morrison J, Tumbahangphe KM, Tamang S, Thapa S, Shrestha D, Thapa B, et al: Effect of a participatory intervention with women's groups on birth outcomes in Nepal: cluster-randomised controlled trial. Lancet 2004, 364:970-979.

32. Schaider J, Ngonyani S, Tomlin S, Rydman R, Roberts R: International maternal mortality reduction: outcome of traditional birth attendant education and intervention in Angola. Journal of Medical Systems 1999, 23:99-105.

33. Foord F: Gambia: evaluation of the mobile health care service in West Kiang district. World Health Stat Q 1995, 48:18-22.

34. Fauveau F, Stewart K, Khan S, Chakraborty J: Effect on Mortality of Community-Based Maternity-Care Programme in Rural Bangladesh. Lancet 1991, 338:1183-1186.

35. Ronsmans C, Vanneste A, Chakraborty J, van Ginneken J: Decline in maternal mortality in Matlab, Bangladesh: a cautionary tale. Lancet 1997, 350:1810-1814.

36. Greenwood AM, Bradley AK, Byass P, Greenwood BM, Snow RW, Bennett S, Hatib-N'Jie AB: Evaluation of a primary health care programme in The Gambia. I. The impact of trained traditional birth attendants on the outcome of pregnancy. J Trop Med Hyg 1993, 93:58-66.

37. Campbell O, Gipson R, Issa AH, Matta N, El Deeb B, El Mohandes A, Alwen A, Mansour E: National maternal mortality ratio in Egypt halved between 1992-93 and 2000. Bull World Health Organ 2005, 83:462-471.

38. Dumont A, Gaye A, de Bernis L, Chaillet N, Landry A, Delage J, BouvierColle MH: Facility-based maternal death reviews: effects on maternal mortality in a district hospital in Senegal. Bull World Health Organ 2006, 84:218-224.

39. Bashir A: Maternal mortality in Pakistan. A success story of the Faisalabad district. IPPF Med Bull 1991, 25:1-3.

40. Bashir A, Aleem M, Mustansar M: A 5-year study of maternal mortality in Faisalabad City Pakistan. Int J Gynecol Obstet 1995, 50(Suppl 2):93-96.
41. Mbaruku G, Bergström S: Reducing maternal mortality in Kigoma, Tanzania. Health Policy Plan 1995, 10:71-78.

42. Kayongo M, Esquiche E, Luna M, Frias G, Vega-Centeno L, Bailey P: Strengthening emergency obstetric care in Ayacucho, Peru. Int J Gynecol Obstet 2006, 92:299--307.

43. Ifenne D, Essien E, Golji N, Sabitu K, Alti-Mu'azu M, Adidu V, Mukaddas M: Improving the quality of obstetric care at the teaching hospital, Zaria, Nigeria. Int J Gynecol Obstet 1997, 59(Suppl 2):37-46.

44. Oyesola R, Shehu D, Ikeh A, Maru I: Improving emergency obstetric care at a state referral hospital, Kebbi state, Nigeria. Int J Gynecol Obstet 1997, 59(Suppl 2):75-81.

45. Gummi FB, Hassan M, Shehu D, Audu L: Community education to encourage use of emergency obstetric services, Kebbi State, Nigeria. Int J Gynecol Obstet 1997, 59(Suppl 2):191-200.

46. Ande B, Chiwunzie J, Akpala W, Oronsaye A, Okojie B, Okolocha C, Omorogbe S, Onoguwe B, Oikeh E: Improving obstetric care at the district hospital, Ekpoma, Nigeria. Int J Gynecol Obstet 1997, 59(Suppl 2):47-53.

47. Chiwuzie J, Okojie O, Okolocha C, Omorogbe S, Oronsaye A, Akpala W, Ande B, Onoguwe B, Oikeh E: Emergency loan funds to improve access to obstetric care in Ekpoma, Nigeria. Int J Gynecol Obstet 1997, 59(Suppl 2):231-236.

48. Chaudhury RH, Chowdhury Z: Maternal mortality in rural Bangladesh: lessons learned from Gonoshasthaya Kendra programme villages. Asia Pac Popul J 2008, 23:55-78.

49. Nasah BT, Leke RJ, Doh AS, Moyo JK, Fomulu J, Njikam OM: The risk approach for reducing maternal mortality: the Yaounde experience. Int $J$ Gynecol Obstet 1991, 36:195-201.

50. Xu Z: China: lowering maternal mortality in Miyun County, Beijing. World Health Stat Q 1995, 48:11-14.

51. Danel I: Maternal mortality reduction in Honduras, 1990 - 1997. A case study. Washington, D.C: World Bank. Latin America and Carribean Region; 1999.

52. Kwast $\mathrm{BE}$ : Reduction of maternal and perinatal mortality in rural and peri-urban settings: what works? Eur J Obstet Gynecol Reprod Biol 1996 69:47-53.

53. Padmanaban P, Raman PS, Mavalankar DV: Innovations and Challenges in Reducing Maternal Mortality in Tamil Nadu, India. J Health Popul Nutr 2009, 27:202-219.

54. Barker CE, Bird CE, Pradhan A, Shakya G: Support to the Safe Motherhood Programme in Nepal: an integrated approach. Reprod Health Matters 2007, 15:81-90.

55. Kayongo M, Rubardt M, Butera J, Abdullah M, Mboninyibuka D, Madili M: Making EmOC a reality-CARE's experiences in areas of high maternal mortality in Africa. Int J Gynecol Obstet 2006, 92:308-319.

56. Islam MT, Hossain MM, Islam MA, Haque YA: Improvement of coverage and utilization of EmOC services in southwestern Bangladesh. Int $J$ Gynecol Obstet 2005, 91:298-305.

57. Fournier P, Dumont A, Tourigny C, Dunkley G, Dramé S: Improved access to comprehensive emergency obstetric care and its effect on institutional maternal mortality in rural Mali. Bull World Health Organ 2009, 87:30-38.

58. Kayongo M, Butera J, Mboninyibuka D, Nyiransabimana B, Ntezimana A, Mukangamuje V: Improving availability of EmOC services in RwandaCARE's experiences and lessons learned at Kabgayi Referral Hospital. Int J Gynecol Obstet 2006, 92:291-298.

59. Santos C, Diante D, Baptista A, Matediane E: Improving emergency obstetric care in Mozambique: The story of Sofala. Int J Gynecol Obstet 2006, 94:190-201.

60. Mushi D, Mpembeni R, Jahn A: Effectiveness of community based safe motherhood promoters in improving the utilization of obstetric care. The case of Mtwara rural district in Tanzania. BMC Pregnancy Childbirth 2010, 10:14

61. Otchere SA, Binh HT: Strengthening emergency obstetric care in Thanh Hoa and Quang Tri provinces in Vietnam. Int I Gynecol Obstet 2007, 99:165-172.

62. Lodhi SK, Sohail R, Zaman F, Tayyab M, Bashir T, Hudsone CN, Khan RL: FIGO save the Mothers Initiative: the Pakistan-UK collaboration. Int J Gynecol Obstet 2004, 87:79-87.

63. Jamisse L, Songane F, Libombo A, Bique C, Faúndes A: Reducing maternal mortality in Mozambique: challenges, failures, successes and lessons learned. Int J Gynecol Obstet 2004, 85:203-212. 
64. Leigh B, Kandeh H, Kanu M, Kuteh M, Palmer I, Daoh K, Moseray : Improving emergency obstetric care at a district hospital, Makeni, Sierra Leone. Int J Gynecol Obstet 1997, 59(Suppl 2):55-65.

65. Olukoya A, Ogunyemi M, Akitoye C, Abudu O, Tijani MA, Epoyun AO, Ahabue CE, Shaba O: Upgrading obstetric care at a secondary referral hospital, Ogun State, Nigeria. Int J Gynecol Obstet 1997, 59(Suppl 2):67-74.

66. Sengeh P, Samai O, Sidique S, Kebbie A, Fofana P, Stephens S: Improving blood availability in a district hospital, Bo, Sierra Leone. Int J Gynecol Obstet 1997, 59(Suppl 2):127-134

67. Samai O, Sengeh P: Facilitating emergency obstetric care through transportation and communication, Bo, Sierra Leone. Int I Gynecol Obstet 1997, 59(Suppl 2):157-164.

\section{Pre-publication history}

The pre-publication history for this paper can be accessed here: http://www.biomedcentral.com/1471-2393/11/30/prepub

doi:10.1186/1471-2393-11-30

Cite this article as: Nyamtema et al.: Maternal health interventions in resource limited countries: a systematic review of packages, impacts and factors for change. BMC Pregnancy and Childbirth 2011 11:30.

\section{Submit your next manuscript to BioMed Central} and take full advantage of:

- Convenient online submission

- Thorough peer review

- No space constraints or color figure charges

- Immediate publication on acceptance

- Inclusion in PubMed, CAS, Scopus and Google Scholar

- Research which is freely available for redistribution

Submit your manuscript at www.biomedcentral.com/submit 